\title{
Processes of Emergence of Systems and Systemic Properties
}

Towards a General Theory of Emergence 
This page intentionally left blank 


\section{Processes of \\ Emergence of Systems and Systemic Properties \\ Towards a General Theory of Emergence}

Proceedings of the International Conference Castel Ivano, Italy 18 - 20 October 2007

editors

Gianfranco Minati

Italian Systems Society, Italy

Mario Abram

Italian Systems Society, Italy

\section{Eliano Pessa}

University of Pavia, Italy 
Published by

World Scientific Publishing Co. Pte. Ltd.

5 Toh Tuck Link, Singapore 596224

USA office: 27 Warren Street, Suite 401-402, Hackensack, NJ 07601

UK office: 57 Shelton Street, Covent Garden, London WC2H 9HE

\section{British Library Cataloguing-in-Publication Data}

A catalogue record for this book is available from the British Library.

\section{PROCESSES OF EMERGENCE OF SYSTEMS AND SYSTEMIC PROPERTIES Towards a General Theory of Emergence \\ Copyright (C) 2009 by World Scientific Publishing Co. Pte. Ltd. \\ All rights reserved. This book, or parts thereof, may not be reproduced in any form or by any means, electronic or mechanical, including photocopying, recording or any information storage and retrieval system now known or to be invented, without written permission from the Publisher.}

For photocopying of material in this volume, please pay a copying fee through the Copyright Clearance Center, Inc., 222 Rosewood Drive, Danvers, MA 01923, USA. In this case permission to photocopy is not required from the publisher.

ISBN-13 978-981-279-346-1

ISBN-10 981-279-346-1

Printed in Singapore. 


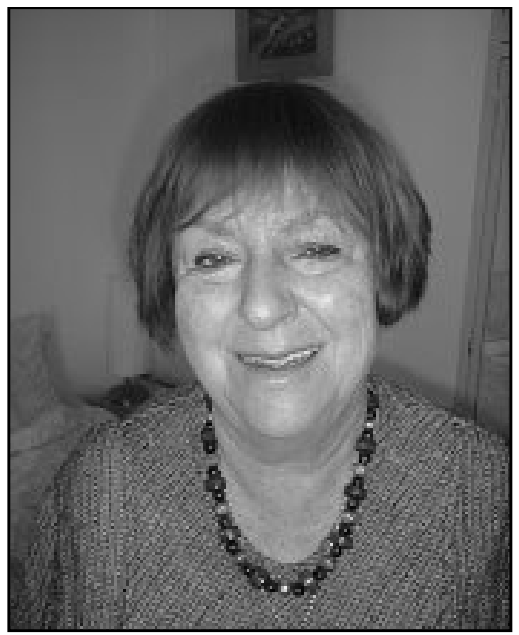

The proceedings of the fourth national conference of the Italian Systems Society (AIRS) are dedicated to the memory of Evelyne Andreewsky, passed away on December 2007. Several members of AIRS had the honour to be her colleague and friend.

Evelyne Andreewsky was born in Paris. She earned an engineering degree in Electronics from E.S.E., Paris, and a "Docteur ès Sciences" degree $(\mathrm{PhD})$ in Computer Science (Neurolinguistic Modelling), from Pierre \& Marie Curie University, Paris VI. She was Senior Researcher at the French National Research Institute I.N.S.E.R.M.

She has switched from (a straight) Computer Scientist career (as research engineer, chief of information processing public labs, consultant for government's policies, UNESCO expert...) to (pure) Research, trying to develop new multidisciplinary systemic approaches to Cognition and Language (over 150 papers in scientific international journals, books, chapters of books + books editor, guest editor of journals). 
She was founder and honorary president of the Systems Science European Union (UES).

She was actively involved in the board of scientific societies, namely AFSCET (French Systems Science Society) and MCX (European Program for Modelling Complexity). She belonged to the editorial board of scientific journals, namely "Cybernetics and Human Knowing" and Res-Systemica. She has organized or co-organized a number of national and international congresses, symposia and summer schools. She has been elected (1999) to Honorary Fellowship of the World Organisation of General Systems and Cybernetics (WOSC), founded by Professor John Rose, and has been invited to give courses or lectures in various countries.

We will never forget her and her dedication to systems science.

Thank you Evelyne. 


\section{PREFACE}

The title of this fourth national conference of the Italian Systems Society (AIRS), Processes of emergence of systems and systemic properties - Towards a general theory of emergence, has been proposed to emphasize the importance of processes of emergence within Systemics. The study of this topic has a longstanding tradition within AIRS. Namely this conference can be considered as a continuation of the previous 2002 conference, Emergence in Complex Cognitive, Social and Biological Systems, and 2004 conference, Systemics of Emergence: Research and Applications.

In the preface of the 2004 conference the editors wrote:

"Emergence is not intended as a process taking place in the domain of any discipline, but as 'trans-disciplinary modeling' meaningful for any discipline. We are now facing the process by which General System Theory is more and more becoming a Theory of Emergence, seeking suitable models and formalizations of its fundamental bases. Correspondingly, we need to envisage and prepare for the establishment of a Second Systemics - a Systemics of Emergence...".

We had intense discussions in the periodic meetings of AIRS, focused on the large, increasing amount of contributions available in the scientific literature about emergence. In this regard we remark that AIRS members were and actually are involved in research projects in several disciplinary fields, having the experience of applying the view of emergence outlined above, for instance, in Architecture, Artificial Intelligence, Biology, Cognitive Science, Computer Science, Economics, Education, Engineering, Medicine, Physics, Psychology, and Social Sciences. As a consequence of this intense activity we felt an increasing need to better specify the principles to be adopted when dealing with this evolving, interdisciplinary study of emergence.

With this point of view in mind, which could be viewed as a generalization of other instances, historically at the basis of birth of different systems societies in the world (e.g., Cybernetics, General System Theory, Living Systems Theory, Systems Dynamics, Systems Engineering, Systems Theory, etc.), in October 2006 the Italian Systems Society approved a Manifesto, available at our web site www.AIRS.it . It relates to our vision of the current situation of the role of world-wide Systems Societies, as well as of problems and perspectives of Systemics. In the Manifesto we outlined some fundamental aspects of our identity, such as the necessary role of disciplinary knowledge for Systemics, as 
well as of inter- and trans-disciplinary knowledge, the meaning of generalization, the need for rigorousness and the non-ideological valence of reductionism.

We quote the concluding statements of the Manifesto:

"The purpose of systems societies should be to identify and, where possible, produce contributions to Systemics taking place in disciplinary and multidisciplinary research, making them general and producing proposals for structuring and generalizing disciplinary results. Examples of theoretical aspects of such an effort are those related the establishment of a General Theory of Emergence, a Theory of Generalization, Logical Philosophical models related to Systemics and the issue of Variety in different disciplinary contexts."

The general theory of emergence we figure out is not a unique, caseindependent and scale-independent approach, having general disciplinary validity. Instead we have in mind different, dynamical and interacting levels of description within a constructivist view able to model processes of emergence, in order not to reduce all of them to a single description, but to introduce multimodeling and modeling hierarchy as a general approach to be used in principle. A related approach has been introduced in literature with the DYnamic uSAge of Models (DYSAM) and logical openness, i.e. meta-level modelling (models of models).

We make reference to a constructivist science, as dealing with the constructive role of the observer in processes of emergence. The latter is related to his/her cognitive model allowing the recognition of acquired systemic properties, which occurs when the hierarchical processes generating these properties cannot be modeled by using traditional causal approaches. In other words, according to a constructivist view on one side the observer looks for what is conceivable by using the assumed cognitive model, and, on the other side, he/she can introduce methodologies allowing the possibility of producing incongruence, unexpected results and inconsistence. The latter process asks for a new cognitive model generating paradigm shifts and new theoretical approaches, such as in the case of abduction, as introduced by Peirce. All this is endowed with a deep, general, cultural meaning when the focus is on scientific aspects where it is possible to test, compare, validate and formulate new explicative theories.

Moreover, we believe that the subject of emergence is a sort of accumulation point of increasing, mutually related conceptual links to disciplinary open questions, such as the ones mentioned in the topics of the conference. 
The study of processes of emergence implies the need to model and distinguish, in different disciplinary contexts, the establishment of structures, systems and systemic properties.

Examples of processes of emergence of systems are given by the establishment of entities which constructivistically the observer detects to possess properties different from those of the component parts, such as in the case of collective behaviors giving rise to ferromagnetism, superconductivity and superfluidity and to social systems such as markets and industrial districts. It must be noted that in a constructivist view the whole is not constituted by parts, but rather the observer identifies parts by using a model in the attempt to explain the whole (observer and designer coincide only for artificial systems). A different partitioning corresponds to different, mutually equivalent or irreducible, models.

Systems do not only possess properties, but are also able, in their turn, to make emergent new ones. Examples of emergence of systemic properties in systems (i.e., complex systems) are given by the establishment of properties such as cognitive abilities in natural and artificial systems, collective learning abilities in social systems such as flocks, swarms, markets, firms and functionalities in networks of computers (e.g., in Internet). Evolutionary processes establish properties in living systems.

The models of these processes introduced so far are based on theories of phase transitions, of bifurcations, of dissipative structures, and of Multiple Systems (Collective Beings). On the one hand the ability to identify these processes allows effectiveness without confusing processes of a different nature but having in common the macroscopic and generic establishment of systems. This concerns a number of disciplinary contexts such as Physics, Cognitive Science, Biology, Artificial Intelligence, Economics. On the other hand the attempt to build a General Theory of Emergence corresponds to Von Bertalanffy's project for a General System Theory. The conference will then focus upon these issues from theoretical, experimental, applicative, epistemological and philosophical points of view.

We take this opportunity to mention an important, even if not explicit, outcome of the conference. The scientific committee and we, the editors, had the duty and benefit of this outcome and now we have the pleasure of sharing it with the readers.

As it is well known, the scientific and cultural level of scientific journals and edited books is assumed to be assured by a good refereeing by the editorial board and the scientific committee. The task is supposed to be quite "easy" 
when dealing with topics having general acceptance in academic and research contexts, robust methodologies, and consolidated literature. Consistency is assumed to be assured, in short, by the complete state of the art, and consequently grounded on the application of well-described approaches, consistent reasoning, supporting examples, validation procedures, so as to get coherent conclusions.

Traditionally, the systemic community (the one we criticize in the Manifesto) has always tolerated low 'grades' in those areas as balanced by the need to break disciplinary well-defined barriers and approaches and encourage focus on new aspects not regulated by classic rules of acceptance. The purpose was to don't take the risk of suffocating ideas able to generate interesting cultural processes despite their imprecise formulation, even presenting an interesting inconsistence. This was the age when to be inter- and transdisciplinary was a challenge (actually, it is still so in several universities). As emphasized in our Manifesto, disciplinary scientific research had the need to become more and more interdisciplinary, independently from roles, efforts and recommendations of system societies.

The challenge for the systemic movement is, in our view, to convert this need into a theoretical result stemming from a General Theory of Emergence intended as a Theory of Change. The challenge is not only at theoretical level, but also at educational level (e.g., in which university department make such a research?). At the same time we have today available an enormous amount of knowledge and we have to face the temptation to explain-all-with-previousknowledge (like in Science). In this context we may lack approaches suitable for recognize and establish new paradigms, inhomogeneous in principle with the old ones. At the same time we lack ways to assure quality levels (e.g. "What if Simplicio had had computers available?").

One consequence of the unavailability of a General Theory of Emergence as a Theory of Change is the unavailability of a robust methodology for evaluating contributions having this mission. The attempt to evaluate each contribution as a disciplinary contribution may imply the lack of appreciation for innovative, inter- and trans-disciplinary systemic meaning. The problem relates to the production of scientific knowledge and educational systems having to deal with an enormous amount of available knowledge by using often old approaches, methodologies and technologies. How to recognize that a wrong, intelligent idea may be more important than a right, not-so-intelligent idea expected to be homologated because of its homogeneity with the established knowledge? 
Is the system community, in force of its historical attention and mission related to inter- and trans-disciplinarity, able to face this challenge in general, i.e. propose innovative approaches and methodologies able to guarantee, test and validate inter- and trans-disciplinary consistency and robustness? We will try to contribute, on the basis of our experience and research activity, to the introduction of proposals and methodologies. The Italian Systems Society is trying to play a significant role in this process.

The conference was articulated in different sessions able to capture both the theoretical aspects of emergence as introduced above and the applicative ones:

1. Emergence in Architecture.

2. Processes of emergence in Economics and Management.

3. Emergence.

4. Emergence in social systems.

5. Emergence in Artificial Intelligence.

6. Emergence in Medicine.

7. Models and systems.

8. Theoretical problems of Systemics.

9. Cognitive Science.

We conclude by emphasizing that we are aware of how much the scientific community focuses on the available knowledge, as a very comprehensible attitude. By the way, we also have the dream of inter-related forms of knowledge, one represented and modelled into the other, in which meanings have simultaneous multi-significance contributing to generate hierarchies allowing to deal with the meaning of human existence. With this dream in mind we use the bricks of science to contribute to make emergent a new multidimensional knowledge.

Gianfranco Minati

AIRS president

Eliano Pessa

Co-Editor

Mario Abram

Co-Editor 
This page intentionally left blank 


\section{PROGRAM COMMITTEE}

G. Minati (chairman) Italian Systems Society

E. Pessa (co-chairman) University of Pavia

L. Biggiero

LUISS University, Rome

G. Bruno

University of Rome "La Sapienza"

V. Coda

"Bocconi" University, Milan

S. Della Torre

Polytechnic University of Milan

V. Di Battista

Polytechnic University of Milan

S. Di Gregorio

University of Calabria

I. Licata

Institute for Basic Research, Florida, USA

M.P. Penna

University of Cagliari

R. Serra

University of Modena and Reggio Emilia

G. Tascini

University of Ancona

G. Vitiello

University of Salerno 
This page intentionally left blank 


\section{CONTRIBUTING AUTHORS}

$\begin{array}{lll}\text { Abram M.R. } & \text { Della Torre S. } & \text { Percivalle S. } \\ \text { Alberti M. } & \text { Di Battista V. } & \text { Pessa E. } \\ \text { Allievi P. } & \text { Di Caprio U. } & \text { Picci P. } \\ \text { Arecchi F.T. } & \text { Di Gregorio S. } & \text { Pietrocini E. } \\ \text { Argentero P. } & \text { Ferretti M.S. } & \text { Pinna B. } \\ \text { Arlati E. } & \text { Filisetti A. } & \text { Poli I. } \\ \text { Avolio M.V. } & \text { Giallocosta G. } & \text { Puliti P. } \\ \text { Battistelli A. } & \text { Giunti M. } & \text { Ramazzotti P. } \\ \text { Bednar P.M. } & \text { Graudenzi A. } & \text { Ricciuti A. } \\ \text { Bich L. } & \text { Gregory R.L. } & \text { Rocchi C. } \\ \text { Biggiero L. } & \text { Guberman S. } & \text { Rollo D. } \\ \text { Bonfiglio N. } & \text { Ingrami P. } & \text { Rongo R. } \\ \text { Bouchard V. } & \text { Lella L. } & \text { Sechi C. } \\ \text { Bruno G. } & \text { Licata I. } & \text { Serra R. } \\ \text { Buttiglieri F. } & \text { Lupiano V. } & \text { Setti I. } \\ \text { Canziani A. } & \text { Magliocca L.A. } & \text { Sevi E. } \\ \text { Carletti T. } & \text { Marconi P.L. } & \text { Sforna M. } \\ \text { Cirina L. } & \text { Massa Finoli G. } & \text { Spataro W. } \\ \text { Colacci A. } & \text { Minati G. } & \text { Stara V. } \\ \text { Collen A. } & \text { Mocci S. } & \text { Tascini G. } \\ \text { D'Ambrosio D. } & \text { Montesanto A. } & \text { Terenzi G. } \\ \text { Damiani C. } & \text { Mura M. } & \text { Trotta A. } \\ \text { David S. } & \text { Odoardi C. } & \text { Villani M. } \\ \text { Del Giudice E. } & \text { Paoli F. } & \text { Vitiello G. } \\ \text { Dell'Olivo B. } & \text { Penna M.P. } & \end{array}$


This page intentionally left blank 


\section{CONTENTS}

Dedication $\quad$ V

Preface vii

Program Committee X xiii

Contributing Authors $\quad$ XV

$\begin{array}{ll}\text { Contents } & \text { xvii }\end{array}$

Opening Lecture

Coherence, Complexity and Creativity 3

Fortunato Tito Arecchi

\section{Emergence in Architecture}

Environment and Architecture - A Paradigm Shift

Valerio Di Battista

Emergence of Architectural Phenomena in the Human Habitation of Space Arne Collen

Questions of Method on Interoperability in Architecture

Ezio Arlati, Giorgio Giallocosta

Comprehensive Plans for a Culture-Driven Local Development:

Emergence as a Tool for Understanding Social Impacts of Projects

on Built Cultural Heritage

Stefano Della Torre, Andrea Canziani

Systemic and Architecture: Current Theoretical Issues

Giorgio Giallocosta 


\section{Processes of Emergence in Economics and Management}

Modeling the $360^{\circ}$ Innovating Firm as a Multiple System

or Collective Being

Véronique Bouchard

The COD Model: Simulating Workgroup Performance

Lucio Biggiero, Enrico Sevi

Importance of the Infradisciplinary Areas in the Systemic Approach

Towards New Company Organisational Models: the Building Industry

Giorgio Giallocosta

Systemic Openness of the Economy and Normative Analysis

Paolo Ramazzotti

Motivational Antecedents of Individual Innovation

Patrizia Picci, Adalgisa Battistelli

An E-Usability View of the Web: A Systemic Method for User Interfaces

Vera Stara, Maria Pietronilla Penna, Guido Tascini

\section{Emergence}

Evolutionary Computation and Emergent Modeling of Natural Phenomena

R. Rongo, W. Spataro, D. D'Ambrosio, M.V. Avolio,

V. Lupiano, S. Di Gregorio

A New Model for the Organizational Knowledge Life Cycle

Luigi Lella, Ignazio Licata

On Generalization: Constructing a General Concept

from a Single Example

Shelia Guberman

General Theory of Emergence Beyond Systemic Generalization

Gianfranco Minati

Uncertainty, Coherence, Emergence

Giordano Bruno

Emergence and Gravitational Conjectures

Paolo Allievi, Alberto Trotta 


\section{Emergence in Social Systems}

Inducing Systems Thinking in Consumer Societies

Gianfranco Minati, Larry A. Magliocca

Contextual Analysis. A Multiperspective Inquiry into Emergence

of Complex Socio-Cultural Systems

Peter M. Bednar

Job Satisfaction and Organizational Commitment:

Affective Commitment Predictors in a Group of Professionals

Maria Santa Ferretti

Organizational Climate Assessment: A Systemic Perspective

Piergiorgio Argentero, Ilaria Setti

Environment and Urban Tourism: An Emergent System

in Rhetorical Place Identity Definitions

Marina Mura

\section{Emergence in Artificial Intelligence}

Different Approaches to Semantics in Knowledge Representation

S. David, A. Montesanto, C. Rocchi

Bidimensional Turing Machines as Galilean Models

of Human Computation

Marco Giunti

A Neural Model of Face Recognition: A Comprehensive Approach

Vera Stara, Anna Montesanto, Paolo Puliti,

Guido Tascini, Cristina Sechi

Anticipatory Cognitive Systems: A Theoretical Model

Graziano Terenzi

Decision Making Models within Incomplete Information Games

Natale Bonfiglio, Simone Percivalle, Eliano Pessa

\section{Emergence in Medicine}

Burnout and Job Engagement in Emergency and Intensive Care Nurses

Piergiorgio Argentero, Bianca Dell'olivo 
The "Implicit" Ethics of a Systemic Approach to the Medical Praxis Alberto Ricciuti

Post Traumatic Stress Disorder in Emergency Workers:

Risk Factors and Treatment

Piergiorgio Argentero, Bianca Dell'Olivo, Ilaria Setti

State Variability and Psychopathological Attractors.

The Behavioural Complexity as Discriminating Factor between

the Pathology and Normality Profiles

Pier Luigi Marconi

\section{Models and Systems}

Decomposition of Systems and Complexity

Mario R. Abram

How many Stars are there in Heaven? The results of a study

of Universe in the light of Stability Theory

Umberto Di Caprio

Description of a Complex System through Recursive Functions

Guido Massa Finoli

Issues on Critical Infrastructures

Mario R. Abram, Marino Sforna

\section{Theoretical Problems of Systemics}

Downward Causation and Relatedness in Emergent Systems:

Epistemological Remarks

Leonardo Bich

Towards a General Theory of Change

Eliano Pessa

Acquired Emergent Properties

Gianfranco Minati

The Growth of Populations of Protocells

Roberto Serra, Timoteo Carletti, Irene Poli, Alessandro Filisetti

Investigating Cell Criticality

R. Serra, M. Villani, C. Damiani, A. Graudenzi,

P. Ingrami, A. Colacci 
Relativistic Stability. Part 1 - Relation Between Special Relativity and Stability Theory in the Two-Body Problem

\section{Umberto Di Caprio}

Relativistic Stability. Part 2 - A Study of Black-Holes

and of the Schwarzschild Radius

Umberto Di Caprio

The Formation of Coherent Domains in the Process of Symmetry Breaking Phase Transitions

Emilio Del Giudice, Giuseppe Vitiello

\section{Cognitive Science}

Organizations as Cognitive Systems.

Is Knowledge an Emergent Property of Information Networks?

Lucio Biggiero

Communication, Silence and Miscommunication

Maria Pietronilla Penna, Sandro Mocci, Cristina Sechi

Music: Creativity and Structure Transitions

Emanuela Pietrocini

The Emergence of Figural Effects in the Watercolor Illusion

Baingio Pinna, Maria Pietronilla Penna

Continuities and Discontinuities in Motion Perception

Baingio Pinna, Richard L. Gregory

Mother and Infant Talk about Mental States: Systemic Emergence of Psychological Lexicon and Theory of Mind Understanding

D. Rollo, F. Buttiglieri

Conflict in Relationships and Perceived Support

in Innovative Work Behavior

Adalgisa Battistelli, Patrizia Picci, Carlo Odoardi

Role Variables vs. Contextual Variables in the Theory

of Didactic Systems

Monica Alberti, Lucia Cirina, Francesco Paoli 